\title{
El epitafio de Ovidio (Trist. III 3.73-76): la complejidad de la deixis al servicio de la sofisticación poética*
}

\author{
Susana González Marín \\ Universidad de Salamanca \\ sana@usal.es \\ ORCID iD: https://orcid.org/0000-0003-2421-5666 \\ The epitaph of Ovid (Trist. III 3.73-76): \\ the complexity of deixis at the service of poetic sophistication
}

\begin{abstract}
El epitafio que Ovidio compone para sí mismo (Trist. III 3.73-76) comienza con el adverbio hic, una posición que atrae inmediatamente la atención sobre la deixis. El hecho de tratarse de una inscripción no real sino literaria determina el análisis de este aspecto tanto en este caso como en otros epitafios de poetas elegíacos; pero Ovidio complica la cuestión atribuyendo a este texto tres situaciones enunciativas distintas: la de un epitafio que figuraría exento en su futuro monumento funerario; la de la carta desde el exilio que dirige a su esposa, donde le comunica sus disposiciones fúnebres; $\mathrm{y}$ la de un poema dentro de un libro dirigido a su lector. El solapamiento de las tres situaciones multiplica las posibilidades de identificar los referentes de los deícticos. El resultado es la comprobación de que probablemente Ovidio explotó esta multirreferencialidad, lo que, además de mostrar su sofisticación, refuerza el carácter metapoético del epitafio.
\end{abstract}

Palabras clave: Ovidio; deixis; epitafios literarios latinos; metapoesía; titulus; libro poético.
The epitaph that Ovid composed for himself (Trist. III 3.73-76) begins with the adverb hic, a position that immediately draws attention to the deixis. The fact of being a non-real inscription but literary determines the analysis of this aspect both in this case and in other epitaphs of elegiac poets; but Ovid complicates the question by attributing to this text three different enunciative situations: that of an epitaph that would appear exempt in his future funerary monument; that of the letter from exile that he addresses to his wife, where he communicates his funeral arrangements; and that of a poem inside a book addressed to his reader. The overlap of the three situations multiplies the possibilities of identifying the referents of the deictics. The result is the verification that Ovid probably exploited this multireferentiality, which in addition to showing its sophistication reinforces the metapoetic character of the epitaph.

Key words: Ovid; deixis; Latin literary epitaphs; metapoetry; titulus; poetic book.

* Este trabajo se ha realizado en el marco del Proyecto de Investigación FFI2017-87037-P financiado por el MINECO. Agradezco a Rosario Cortés Tovar y Agustín Ramos Guerreira sus sugerencias, así como a los informantes anónimos y al editor de la revista su revisión.

Copyright: (C) 2019 CSIC. Este es un artículo de acceso abierto distribuido bajo los términos de la licencia de uso y distribución Creative Commons Reconocimiento 4.0 Internacional (CC BY 4.0). 
Cómo citar este artículo / Citation: González Marín, Susana 2019: «El epitafio de Ovidio (Trist. III 3.73-76): la complejidad de la deixis al servicio de la sofisticación poética», Emerita 87 (1), pp. 99-121.

\section{La importancia de la deixis en el epitafio de Ovidio}

Ovidio redactó su propio epitafio en Trist. III 3.73-76. El poeta, tan enfermo en Tomis que se ve incapaz de escribir, dicta una carta para su esposa, que permanece en Roma. Ve de cerca la muerte y teme que su cuerpo tenga que recibir sepultura en el lugar donde ha sido relegado; por eso solicita a su mujer que recoja sus huesos, los deposite a las afueras de Roma y coloque en su tumba el epitafio que él le envía (Trist. III 3.65-80):

ossa tamen facito parua referantur in urna: sic ego non etiam mortuus exul ero.

Non uetat hoc quisquam: fratrem Thebana peremptum supposuit tumulo rege uetante soror.

Atque ea cum foliis et amomi puluere misce, inque suburbano condita pone solo; quosque legat uersus oculo properante uiator, grandibus in tituli marmore caede notis:

HIC'EGO·QVI-IACEO·TENERORVM·LVSOR·AMORVM

INGENIO $\cdot$ PERII $\cdot$ NASO $\cdot$ POETA $\cdot$ MEO

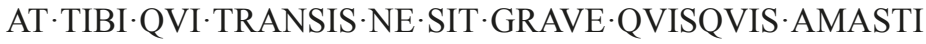

DICERE'NASONIS'MOLLITER $\cdot$ OSSA·CVBENT

hoc satis in titulo est. etenim maiora libelli

et diuturna magis sunt monumenta mihi,

quos ego confido, quamuis nocuere, daturos

nomen et auctori tempora longa suo ${ }^{1}$.

Las inscripciones funerarias compuestas por poetas para sí mismos, como es este caso, cuentan con una larga tradición previa, que se remonta a Nosis $(A P$ VII 718$)$ y fue prolongada por Calímaco ( $A P$ VII 415$)$ o Meleagro ( $A P$ VII 417). Se esperaba, de los epigramatistas especialmente, que los autores redactaran sus propios epitafios, con los que a veces cerraban sus libros de poesía (Dahlmann 1963, pp. 628-629).

\footnotetext{
${ }^{1}$ Owen (ed.) 1915.
} 
En el ámbito latino Gelio (I 24) transmite los epitafios de Nevio, Plauto y Pacuvio, probablemente los tres tomados del De poetis de Varrón; y Cicerón (Tusc. I 34 y 117; Cato 73) y Suetonio -a través de Donato- (Vita Vergilii 36) los de Ennio y Virgilio respectivamente ${ }^{2}$. Todos ellos se atribuyeron a los propios poetas.

En condiciones diferentes, integrados en poemas más amplios, aparecen epitafios en varios géneros poéticos latinos: en la elegía naturalmente, siempre consciente de su relación etimológica con la poesía de lamento (Maltby 1991, pp. 201-202), y en la épica y la lírica3 ${ }^{3}$ Ovidio dedica varios a seres distintos (incluido el papagayo de Corina) ${ }^{4}$ además del suyo propio en Tristia. Como él, Tibulo (I 3.55-56), Propercio (II 13.35-36) y Lígdamo ([Tib.] III 2.27-30) incorporaron a sus poemas sendos epitafios para sí mismos ${ }^{5}$.

Todos estas inscripciones comparten un rasgo común: no son reales; pero lo que las distingue de las auténticas no es el contenido, ni el verso, ni la expresión formal, ni siquiera el hecho, sin duda relevante, de que han sido compuestas en vida por la persona a la que se van a dedicar, sino sobre todo por una característica que se sitúa en el terreno de la pragmática: no son inscripciones exentas colocadas sobre un monumento funerario estable -sea este del tipo que sea- que el transeúnte encuentra en su camino, sino que

${ }^{2}$ Las biografías literarias griegas también incluían epitafios teóricamente redactados por los propios poetas para sus tumbas. Las inscripciones de Plauto y Nevio se consideran apócrifas; no hay tanta unanimidad en el caso de Pacuvio, aunque Dahlmann 1963, pp. 649-652 tampoco la juzga auténtica.

${ }^{3}$ Sobre la inserción de textos epigráficos en la literatura cf. Ramsby 2007, pp. 17-38 y Dinter 2011. La proliferación de inscripciones insertas en obras poéticas en época augústea se ha relacionado con el auge «epigráfico» que en ese momento vivió Roma; cf. Nelis-Clément y Nelis 2013. Lamentablemente en la elaboración de este trabajo no se ha podido tener en cuenta el libro Tombs of the Ancient Poets: Between Literary Reception and Material Culture, editado por N. Goldschmidt y B. Graziosi (Oxford 2018), publicado cuando la versión definitiva del artículo ya se había entregado.

4 Ramsby 2005, p. 368, n. 14 enumera además del de Tristia estos: Ep. II 147-148; VII 195-196; XIV 129-130; XV 183-184; Met. II 327-328, XIV 443-444; Fast. III 549-550; Am. II 6.61-62; III 9.67-68; aunque la inscripción de Ep. XV, la de Safo, no es funeraria sino votiva (Houghton 2009, p. 143).

5 Sobre los epitafios en la elegía latina cf. Schmidt 1985; Ramsby 2007; Houghton 2013, que en p. 349, n. 2 aporta bibliografía útil. Sobre Ovidio en particular cf. Herescu 1958, Ramsby 2005, Ingleheart 2015. Se citarán a lo largo del trabajo otros estudios que, a propósito de otro tema o con un enfoque más amplio, también son útiles para el epitafio de Tristia. 
están desligadas de su situación propia y original; se han incluido en un poema cuyo soporte es un libro, un objeto también, pero de índole muy diferen$t^{6}$. En efecto, en un texto poético, por el hecho mismo de serlo, el marco referencial no está fijado de la misma manera que en un discurso no literario ${ }^{7}$.

En este aspecto Ovidio ofrece una poesía de la mayor complejidad. Para empezar, su juego no se reduce a una contraposición entre la situación pragmática real de un epitafio y la del poema en el que se inserta. En realidad son tres las situaciones pragmáticas implicadas: la del epitafio; la de la carta -pues como tal se presenta-; y la del poema, que es parte de un libro cuyo soporte es un rollo de papiro -la materialidad del libro no es un factor desdeñable-. En principio, siempre se trata de textos escritos y en todos los casos la recepción se produce a distancia del tiempo de codificación, como lo llama Levinson (1989, p. 65). En consecuencia, el emisor está siempre ausente, aunque se haga presente de alguna manera gracias a la lectura. Cuando Ovidio redacta Trist. III 3 está fuera de Roma y quiere volver allí, al menos una vez muerto; pero aunque consiga que sus restos mortales regresen, su presencia será un tanto limitada: un epitafio en una tumba es la expresión de una ausencia, como lo es una carta (aún más si no es autógrafa sino dictada, como señala Hardie 2002, p. 289) y lo es también un libro ${ }^{8}$. Esta cuestión se relaciona directamente con un problema nuclear en el análisis de la obra ovidiana en conjunto y en su poesía del exilio en particular, la tensión entre ausencia y presencia del poeta, tal y como ha establecido Hardie en Ovid's Poetic of Illusion'. Sin embargo, a

${ }^{6}$ Dinter 2011, pp. 8-12 aborda la relación entre inscripción y literatura desde el marco teórico de la llamada «intermedialidad», que abarca desde la inclusión explícita de inscripciones (como es nuestro caso) a lo que él llama «medial quotations», que evocan el entorno epigráfico y que no siempre son fácilmente discernibles dentro del texto (estas constituyen su principal foco de interés). La presencia de manifestaciones epigráficas más o menos explícitas, a semejanza de lo que ocurre con las écfrasis, señala el solapamiento parcial de dos sistemas semióticos distintos, expresión que toma de Barchiesi (1997, p. 278), lo que implica una reflexión autoconsciente sobre las diferencias propias de cada medio. Ramsby 2007, pp. 5-7, sin embargo, descarta como presupuesto teórico la comparación con la écfrasis.

${ }^{7}$ Cf. Schmidt 1987, p. 207: «El marco de referencia que conviene para las aserciones de los textos literarios no está fijado o, al menos, no lo está de manera unívoca».

8 Prueba de la importancia de esta cuestión en el libro III de Tristia es el primer poema, en el que no habla el poeta sino el libro cuando llega a Roma; cf. Newlands 1997, pp. 59-60.

${ }^{9}$ Hardie 2002, p. 17: «At the point when funerary epigrams are detached from his original function, released from their unique stone resting-place to circulate in indefinitely reproducible 
pesar de este punto de partida común, las tres situaciones presentan diferencias esenciales, como veremos ${ }^{10}$.

Confirman la importancia de estas cuestiones pragmáticas las palabras de Oomen (1987, pp. 143-144) referidas a la deixis de lugar y de tiempo y a sus diferencias según se trate de un acto enunciativo oral, uno escrito o uno poético: «En la comunicación oral, el destinatario sabe a qué tiempo se refiere el hablante, puesto que tanto él como el hablante están simultáneamente presentes, y conoce también normalmente el lugar en el que se encuentra el hablante. En la comunicación escrita, el hablante debe definir su localización en el espacio y en el tiempo si quiere hacer referencia a ella. En poesía, sin embargo, un hablante puede utilizar, y utilizará, el tiempo presente sin especificar un punto de referencia al que sea posible referirse...; podríamos hablar ahora de una multiplicación de las dimensiones del espacio y el tiempo».

Es especialmente interesante que Oomen esté hablando de la deixis de lugar y de tiempo porque Ovidio comienza así el epitafio: hic ego qui iaceo...; es una variante de las acostumbradas fórmulas hic situs est, hic iacet, o hic iaceo, aunque la forma verbal en primera persona es menos frecuente ${ }^{11}$. Pero su colocación constituye una ligera anomalía respecto a lo más habitual en las inscripciones latinas auténticas: Lassère (2005, I, pp. 230 y 240) apunta que este tipo

papyrus copies, there arises a double absence, as the text now substitutes for the absent (or fictious) monument, itself a substitute for the presence of the once living person».

${ }^{10} \mathrm{La}$ coexistencia de tres actos enunciativos distintos y sus respectivas situaciones pragmáticas no es la única complicación: el hecho de que la carta se haya dictado a un tercero implica la existencia de otro acto enunciativo, esta vez oral, previo a la escritura. Además, en la antigüedad la lectura en voz alta de un epitafio -prevista habitualmente en la propia inscripción: el transeúnte leerá en voz alta el texto- constituye al fin y al cabo otro acto enunciativo que «revive» de alguna manera la voz del difunto (Cf. Svenbro 1988, pp. 53-73; Hardie 2002, p. 91). Y si el lector piensa que realmente Ovidio pronunció en voz alta estos versos al dictarlos, percibe en ellos una inmediatez inusual, como dice Hardie (2002, p. 289), pues al leerlos está reproduciendo el acto de habla del poeta, prestándole su voz. Pero aquí nos limitamos a los actos escritos pues el acto enunciativo oral del dictado de la carta está de alguna manera subordinado al escrito; el escriba no es un auténtico receptor sino solo un intermediario entre Ovidio y su esposa, que sigue siendo la receptora. Este hecho es relevante especialmente de cara al juego entre oralidad y textualidad, pero no tanto de cara a la deixis. Otra cosa es la lectura prevista en voz alta del epitafio por parte del transeúnte; como veremos más adelante, en ella se producen cambios que sí afectan a la deixis.

${ }^{11}$ Lascu 1971, p. 216 aporta algunos ejemplos. Sobre esta cuestión, que afecta a la deixis de personas, volveremos más adelante. 
de expresiones suele aparecer al final y no al principio. Es pertinente señalar que hic ocupa también la posición inicial en el epitafio de Tibulo I 3 y en las dos inscripciones funerarias de Metamorfosis: la de Faetón (II 327-328) y la de Cayeta (XIV 443-444) ${ }^{12}$. Además, también es notable que hic, aquí en una subordinada de relativo (en los otros textos ovidianos la oración no es subordinada), haya sido desplazado de su oración y separado de ella por el pronombre $e g o^{13}$, otro deíctico en lugar destacado, reforzado por el posesivo meo de primera persona, que ocupa la otra posición relevante, la última.

Así pues, todo coincide en destacar la importancia de la deixis. Inevitablemente nos preguntamos por la identificación del referente de hic y de los otros deícticos, que no es necesariamente unívoca puesto que está determinada por el acto enunciativo correspondiente. Dado que aquí están implicadas tres situaciones pragmáticas distintas para el epitafio -ligado a un monumento funerario, en el marco de la carta escrita a su esposa, y, finalmente, contemplado dentro del libro III de Tristia-, nuestro propósito es analizar los efectos de este solapamiento y constatar si, como dice Oomen, existe una multiplicación de las dimensiones del espacio y del tiempo acorde con la enorme sofisticación y complejidad de Ovidio.

\section{Identificación de los referentes de los deícticos}

Cuando encontramos hic en los epitafios inscritos en los monumentos funerarios, es decir, en el lugar original en el que fueron colocados para cumplir su función, esencialmente conmemorativa, el referente del adverbio depende de la colocación del monumento que sirve de soporte: señala el emplazamiento de la tumba en la que está inscrito el texto. Según la terminología de Diessel (1999, pp. 94-95) $)^{14}$, hic sería un exofórico, un deíctico que apunta a una entidad ajena al discurso y que pertenece a la situación comunicativa en la que se encuentran

12 Podría ser interesante el estudio de la relación del epitafio de Trist. III 3 con los incluidos en las Heroidas, especialmente en lo que concierne a la situación enunciativa de los poemas, puesto que las inscripciones funerarias de sus heroínas son supuestamente autógrafas; así, como una nueva heroína, Ovidio escribe o, mejor dicho, dicta, una carta en la que incluye un epitafio para sí mismo.

${ }^{13}$ En latín hay otros casos de este desplazamiento, p. ej., Cic., Q. Rosc. 14.1.

${ }^{14}$ Advertimos de que la teoría de Diessel se refiere a adjetivos y pronombres demostrativos, de manera que algunas de las condiciones que establece para los distintos usos de los 
ambos interlocutores, en este caso el propio Ovidio y el transeúnte que pasa delante de la inscripción. A este se refiere el tibi del v. 75, cuyo referente sería el sujeto de las formas verbales de segunda persona en ese verso.

En cuanto a la deixis de las personas, el epitafio de Ovidio no se desvía en lo fundamental de uno auténtico. Es cierto que comienza hablando en primera persona de sí mismo, aunque para hablar del muerto sea más frecuente el uso de la tercera persona; pero hay también ejemplos del empleo de la primera (Lascu 1971, pp. 215-216). En los versos 73-74 Ovidio adopta para referirse a sí mismo procedimientos deícticos: el ego y el posesivo meo más las formas verbales en primera persona de iaceo y perii; pero la deixis, puesto que tiene un referente variable, no es suficiente para cumplir la función conmemorativa que se le supone y el poeta añade la información necesaria: su nombre y el elemento definitorio que quiere que se recuerde: tenerorum lusor amorum, Naso poeta. En el v. 75 el at imprime un cambio evidente: le sigue inmediatamente un pronombre de segunda persona (tibi) y dos verbos en segunda persona (transis, amasti) que apuntan al destinatario, sea este quien sea; en estos dos versos, las palabras que se ruega al transeúnte que pronuncie, Ovidio ya no se refiere a sí mismo a través de la deixis (procedimiento habitual en los epitafios reales, donde el destinatario pasa a ocupar la primera persona y el difunto la segunda ${ }^{15}$ : sit tibi terra leuis; ossa tibi bene quiescant ${ }^{16}$ ) sino que recurre de nuevo a su nombre propio (Nasonis molliter ossa cubent $)^{17}$, con el que firmaba sus obras amorosas ${ }^{18}$. La ausencia de pro-

deícticos no son pertinentes para hic, que es un adverbio; sin embargo, el hecho de que proceda de un demostrativo justifica la aplicación de sus categorías a este caso.

${ }^{15}$ Ya hemos visto que la cuestión es complicada de partida porque los epitafios dejan escrito el guión para un futuro acto enunciativo oral: el del transeúnte que encuentra la inscripción y la lee en voz alta, rindiendo de esta manera al muerto un tributo.

${ }^{16}$ Los testimonios conservados de esta expresión en epitafios son de fecha posterior, lo que se ha interpretado como ejemplos de influencia del poeta (Lattimore, 1942, pp. 71-72), p. ej. CE 1458.

${ }_{17}$ Remitimos a la aclaración de Siewierska 2004, pp. 1-2: la categoría gramatical de persona, en el caso de la primera y segunda, indica el papel de emisor o destinatario que asume cada participante en el discurso; en ciertas situaciones los hablantes pueden referirse a ellos mismos y a sus destinatarios por sus nombres propios, sus lazos de parentesco, sus títulos, sus ocupaciones, etc. El ejemplo aducido es ilustrativo: una madre regaña a su hijo diciendo «Mamá se va a enfadar con Juan».

${ }^{18}$ Cf. Oliensis 1997, pp. 185-186: Nasón es un nombre que será dicho por otros, implica una alienación que es común al autor de cartas y al autor: ser autor implica separar la persona que habla y escribe de la figura pública a la que se lee, de la que se habla o se escribe. 
cedimientos deícticos implica la ausencia de Ovidio de la situación pragmática prevista para el futuro.

Por otro lado, en los epitafios auténticos la segunda persona, que designa al receptor que está ante el epitafio y es capaz de leerlo, se convierte en el punto de referencia temporal del enunciado. Incluso en aquellos casos en los que el verbo iaceo está en primera persona, el tiempo al que se refiere el presente no es el del emisor, sino el momento o los momentos cualesquiera en los que el receptor, la segunda persona, realiza la lectura de la inscripción $\mathrm{y}$, en consecuencia, cumple con la función conmemorativa inherente al epitafio ${ }^{19}$. Esto solo puede suceder con un verbo como iaceo, que además de ser de estado es atélico: no incorpora la idea de un límite temporal para la acción. De esta manera su mensaje seguirá siendo válido a pesar de que transcurran muchos años.

Pero la separación del texto de la inscripción del soporte al que en teoría se destina transforma este marco referencial. Igual que el referente del hic ya no está determinado y puede $\operatorname{variar}^{20}$, también los otros elementos de la deixis pueden verse afectados.

El epitafio forma parte de la carta, dictada a un tercero -su enfermedad le impide escribirla él mismo-, que dirige a su esposa dejando constancia de sus últimas voluntades. El emisor es el marido, Ovidio, en el exilio; y la segunda persona y receptora, su esposa en Roma. Por otra parte, los tiempos verbales de la inscripción se sitúan en un momento que aún no ha llegado cuando Ovidio escribe su carta. Siempre considerando el epitafio dentro de este marco, el referente del hic está relativamente precisado por las instrucciones previas de Ovidio para que coloque sus restos mortales en una urna a las afueras de Roma, suburbano solo (v. 70). Dentro de la categorización de Diessel (1999, p. 96) hic es un anafórico: su referente se sitúa en el discurso previo. Su posición destacada se debe a que el lugar de su sepultura es un elemento fundamental de su mensaje: sus huesos descansarán a las afueras

19 Svenbro 1988, pp. 53-73, especialmente 72: «La voix du lecteur est le référent éternellement renouvelable grâce auquel l'inscription se réalise dans sa plénitude».

${ }^{20}$ Curiosamente el epitafio de Ovidio se ha llegado a utilizar como si fuera real y se ha reubicado en lugares diferentes: p. ej., al pie de la estatua de bronce de Ettore Ferrari en Constanza, erigida en 1887; resulta irónico que un epitafio concebido por el poeta para su tumba en Roma acabara sobre un monumento en el lugar de su exilio. Cf. Trapp 1973 sobre la historia de las leyendas surgidas alrededor de la hipotética tumba de Ovidio. 
de Roma, y no en Tomis, un lugar perdido y alejado del mundo civilizado; después de muerto, Ovidio ya no será un exiliado y volverá a Roma.

En tercer lugar, la carta que incluye el epitafio es un poema que pertenece a un libro, Tristia III. La situación pragmática de este acto de enunciación es diferente, por tanto, a la anterior. Ovidio, como poeta, se dirige a un lector, que ha podido leer los poemas previos del libro III, o puede que lo haya leído ya una vez entero o incluso que ya conozca los cinco libros de Tristia; también es probable que haya tenido contacto con otras obras de Ovidio además de con el Ars y con las de otros poetas.

Como ya hemos dicho, la posición inicial del hic en este epitafio haría recordar al lector de poesía un poema de Tibulo (I 3), aquel en el que cuenta que durante una expedición con Mesala cae enfermo en Feacia, lo que le impide proseguir el viaje; imagina que la muerte le llega allí y que, alejado de su patria, su familia y su amada, va a recibir sepultura en tierra extraña; a la vista de ello compone un epitafio para esa ocasión (I 3.54-56):

fac lapis inscriptis stet super ossa notis:

HIC IACET IMMITI CONSVMPTVS MORTE TIBVLLVS

MESSALLAM TERRA DVM SEQVITVRQVE MARI

Puesto que se trata de una inscripción inserta en un poema, el hic inicial, como en el caso de Trist. III 3, puede analizarse como anafórico, en este caso de Feacia (Tib. I 3.3: me tenet ignotis aegrum Phaeacia terris). Como en Ovidio, la posición del deíctico es acorde a la relevancia de su referente. No hace falta decir que las situaciones descritas por ambos poetas son similares y que los contactos entre los dos poemas no se limitan a los epitafios: Tibulo y Ovidio están en un lugar lejano, alejados de la familia y de la patria, temen la muerte y que sus restos deban descansar allí.

Ovidio deliberadamente - a ello apuntan las enormes coincidencias (Huskey 2005)- evoca el poema de Tibulo y da vía libre a una nueva interpretación del hic de su epitafio, que pasaría a indicar el lugar alejado en el que Ovidio vive desterrado, Tomis. En este caso el adverbio sería un ejemplo del uso que Diessel (1999, pp. 105-107) llama 'recognitional': estos deícticos no se refieren a elementos del entorno de la situación comunicativa (exofóricos) ni a referentes previamente mencionados en el discurso (anafóricos), sino a entidades que no han aparecido antes en el texto pero que pueden ser identificadas gracias al conocimiento compartido por emisor y receptor. 
Sin duda el interés de Ovidio es que el lector compare su inscripción con la de Tibulo; por eso hace comenzar la suya de la misma manera pero añade una nueva posible lectura del hic, para luego destacar el contraste entre la situación de Tibulo, que imagina su muerte en Feacia, una tierra que ofrece una imagen amable y con un toque de ficcionalidad gracias a la Odisea (Huskey 2005, p. 370), y sus propias circunstancias, en las que el lugar en el que teme morir se describe con tintes negros y es completamente real ${ }^{21}$.

De manera similar, el lector de Ovidio podría recordar la inscripción funeraria, también encabezada por un hic, dedicada a Faetón en Metamorfosis. Tras la desastrosa conducción del carro del Sol, las Náyades dan sepultura a Faetón, que ha caído en un sitio muy alejado de su punto de partida, es más, en otro mundo distinto ${ }^{22}$, y componen su epitafio, que marca el lugar (Met. II 323-328):

quem procul a patria diuerso maximus orbe

excipit Eridanus fumantiaque abluit ora

Naides Hesperiae trifida fumantia flamma

corpora dant tumulo, signant quoque carmine saxum:

HIC SITVS EST PHAETHON CVRRVS AVRIGA PATERNI

QVEM SI NON TENVIT MAGNIS TAMEN EXCIDIT AVSIS

Gracias a esta inscripción, la madre y las hermanas del desdichado Faetón, tras recorrer el mundo entero, pueden localizar su tumba y llorarle. La terrible suerte del muchacho, golpeado por el rayo de Júpiter, es similar a la de Ovidio, que recurre varias veces a esta imagen (fulmen) para referirse a su destino (Trist. I 1.72; I 3.11; II 179; III 4.6; IV 3.69; V 2.53; V 3.31) (VideauDelibes 1991, pp. 239 y 258). Y su muerte lejos de la patria representa una situación similar a la de Ovidio en el exilio (Trist. III 3.3 y 13); la comparación entre ambos es explícita en Trist. I 1.79-8023. Todo ello constituye un

${ }^{21}$ La complejidad de la deixis no es la única diferencia entre ambos epitafios; entre otras cosas, el de Ovidio tiene un acusado carácter metapoético que está ausente en el de Tibulo. Huskey 2005 analiza en detalle las relaciones complejas entre estos textos y $\mathrm{Am}$. III 9, donde Ovidio, lamentando la muerte de Tibulo, aclara que no murió en Feacia y cierra el poema dedicándole un epitafio. Por otra parte, es un ejemplo de cómo la poesía del exilio se convierte en expresión inmediata de la vida del poeta, cf. Schmidt 1985, p. 328; Hardie 2002, pp. 283-285.

${ }^{22}$ Comparar Met. II 323 y Trist. III 14.26 y IV 2.69.

${ }^{23}$ Cf. Claasen 2008, pp. 164-184 sobre la utilización y reutilización de la mitología en la poesía del exilio. 
segundo argumento a favor de la identificación de hic con el lugar apartado de su destierro.

Con aún más probabilidad el lector de Trist. III 3 estaría en condiciones de percibir que algunas de las ideas y expresiones que Ovidio utiliza en su epitafio son variantes de fórmulas epigráficas funerarias que el poeta emplea en otros lugares de la obra para representar su situación de exiliado en ese momento, que él considera equivalente a la de un muerto. La identificación de ambas circunstancias impregna toda la poesía del exilio y el vocabulario utilizado busca hacer visible esta imagen ${ }^{24}$.

Eso es lo que ocurre con los verbos utilizados en los vv. 73-74, iaceo y perii. Iaceo, también en presente y en primera persona, ha aparecido poco antes (III 3.13) referido a su circunstancia de exiliado en un lugar apartado: lassus in extremis iaceo populisque locisque; y reaparecerá en IV 1.85: hic ego sollicitae iaceo nouus incola sedis ${ }^{25}$.

En cuanto a pereo, no es un verbo muy frecuente en las inscripciones funerarias. Pero, por una parte, evoca la elegía amorosa, puesto que los poetas lo han utilizado para referirse a los dolores producidos por el amor (p. ej., Prop. I 6.27: multi longinquo periere in amore libenter). Y por otra, Ovidio lo emplea en numerosas ocasiones cuando habla de su situación como exiliado en Tomis. Así hace en Trist. II 1.2: ingenio perii qui miser ipse meo. Y en el mismo poema III 3 (vv. 52-53) ya lo ha usado para describir su desgracia ${ }^{26}$ : Cum patriam amisi, tunc me periisse putato: / et prior et grauior mors fuit illa mihi.

En estos casos, donde iaceo y perii -es sabido que pereo pertenece a esa clase de verbos cuyo perfecto, con valor resultativo, se traduce generalmente como una acción cuyo efecto se percibe en el presente (ErnoutThomas $1972^{2}$, p. 123)- se utilizan para hablar de su destierro, la deixis temporal remite al tiempo presente del emisor: Ovidio, cuando escribe

${ }^{24}$ Videau-Delibes, 1991, pp. 333-364. Claasen 1996 estudia la relación entre exilio y muerte en Cicerón, Ovidio y Séneca. Para la relevancia de esta imagen en el poema concreto Trist. III 3, cf. Ingleheart 2015, pp. 287-289 y 291, donde señala la utilización de la figura trágica de Polinices en los vv. 67-68. Gómez Pallarés (1998) considera fúnebre la obra en conjunto.

${ }_{25}$ Obsérvese en este verso la repetición del deíctico hic inicial seguido inmediatamente por el pronombre personal ego, sujeto de iaceo.

${ }^{26}$ Ingleheart 2015, p. 294. Más ejemplos de pereo en este sentido y de perdo, del que pereo se considera la pasiva, en Videau-Delibes 1991, pp. 359-360. 
III 3, es un muerto en vida. ¿Qué pasa con estas mismas formas verbales que aparecen en el epitafio? Como ya dijimos, si formaran parte de una inscripción que se encontrara ligada al monumento funerario, se referirían, no al momento de la composición del texto, sino al de la lectura, sea cual sea. Pero aquí se usan en un epitafio inserto en una carta que es un poema, en una situación pragmática diferente, así que el lector, llamado por la semejanza de la expresión empleada en el mismo poema para describir otras circunstancias, podría leer en los dos primeros versos del epitafio el presente iaceo y el resultativo perii como referidos, al igual que en los otros pasajes, al tiempo de codificación, es decir, al tiempo en el que está viviendo su exilio ${ }^{27}$.

Esta interpretación puede contribuir a explicar la elección de Ovidio de la primera persona iaceo en vez de la más habitual tercera, iacet. Tibulo no utiliza ni la primera ni la segunda persona en su inscripción de I 3, sino la tercera. A diferencia de él, Ovidio redacta un epitafio en el que las personas están fuertemente marcadas: ego, meo, at tibi en posiciones relevantes. Las formas verbales en primera persona otorgan al poeta una presencia que no corresponde a la de un difunto: en efecto, en el momento de redactar el epitafio, Ovidio es un muerto, pero aún en vida.

Por otra parte, la segunda persona que designa a su hipotético receptor (tibi qui transis ... quisquis amasti), una fórmula de apelación al transeúnte característica de este tipo de inscripciones, no se refiere simplemente, como sucedería en un epitafio auténtico, a todo el que pase por allí. Al pronombre le sigue no solo la habitual subordinada de relativo qui transis, sino otra -quisquis amasti-introducida por un relativo indeterminado que señala que el referente de la segunda persona alguna vez ha $\operatorname{amado}^{28} \mathrm{y}$, en consecuencia, es un probable lector de su Ars amatoria, en cuyo comienzo se emplea también un indefinido (Ars I 1-2) ${ }^{29}$ : Si quis in hoc artem populo non nouit amandi, / hoc legat et lecto carmine doctus amet.

27 Por otra parte, esta interpretación explica mejor la expresión ingenio perii ... meo, donde ingenio meo se ha tomado como la causa de su muerte, aunque en realidad es la de su desgracia y la de su hipotética muerte sería la enfermedad.

${ }^{28}$ Herescu 1958, p. 440 se pregunta quién no ha amado alguna vez. Según él, el poeta está apelando a todo el mundo frente a la condena de un solo hombre, Augusto.

${ }^{29}$ Cf. Ingleheart 2015, p. 295. Más adelante sumaremos a esta expresión otras que apuntan a la autodefinición del poeta como autor de elegía amorosa. 
Incluso la remodelación de la habitual fórmula dic rogo de los epitafios transformada en tibi ... ne sit graue... dicere, recuerda la petición que el propio libro hace a sus lectores en el primer poema (Trist. III 1.19-20): dicite lectores, si non graue, qua sit eundum, / quasque petam sedes hospes in Vrbe liber.

La posible identificación de la segunda persona con un lector no del epitafio sino de su obra abre paso -nuevo ejemplo de multirreferencialidad- a otra lectura del deíctico hic basada en los versos que siguen al epitafio; estos se concentran en la función conmemorativa recurriendo a la identificación, tan frecuente en los poetas augústeos, de los libros con monumentos capaces de garantizar a sus autores la pervivencia (III 3.77-80):

hoc satis in titulo est. etenim maiora libelli et diuturna magis sunt monumenta mihi, quos ego confido, quamuis nocuere, daturos nomen et auctori tempora longa suo.

Los textos básicos que ilustran esta concepción son de todos conocidos: Hor., Carm. III 30, Prop. III 2.19-26 (que Ingleheart 2015, p. 296 considera un modelo para el texto de Ovidio) y el propio final de las Metamorfosis (XV 868-879), del que solo reproducimos los dos últimos versos, donde se proyecta una imagen de presencia perpetua y una reencarnación del poeta en sus futuros lectores: ore legar populi, perque omnia saecula fama, / siquid habent ueri uatum praesagia, uinam ${ }^{30}$.

Como hemos dicho, el monumento fúnebre constituye un signo de la presencia ausente del muerto (Hardie 2002, pp. 81-84 y 91): la lectura en voz alta de la inscripción por parte del paseante revive la voz del difunto. De manera similar, de cara a la función conmemorativa el lector es necesario en una obra poética. Así pues, como en los otros textos, los libelli constituyen el auténtico monumentum que permitirá la pervivencia del poeta ${ }^{31}$.

${ }^{30}$ Sobre la complejidad de este texto, incrementada por la lectura del pasaje virgiliano de la muerte de Dido en Aen. IV, especialmente vv. 684-685, cf. Hardie 2002, pp. 91-97.

${ }^{31}$ Por supuesto la consideración de la monumentalidad de la poesía permite ciertas interpretaciones políticas. P. ej., Ingleheart 2015, p. 299: Ovidio considera la poesía como un procedimiento alternativo y competitivo de alcanzar la inmortalidad frente a la monumentalidad material fomentada por Augusto. 
En la comprensión del texto el término titulus es clave. Este sustantivo empezó a usarse en época augústea (antes era poco frecuente, en la obra de Cicerón, p. ej., solo aparece dos veces). En principio, denomina materiales que sirven de soporte a textos que indican o identifican algo o a alguien y probablemente a partir de ahí pasó a designar también esos textos de carácter presentativo (Moussy 1997, p. 5). En consecuencia, fue uno de los nombres empleados para las inscripciones y, puesto que estas con frecuencia servían para la presentación e identificación de objetos y personas, adquirió también el sentido de 'título honorífico' o 'distinción'. Esta dualidad general -soporte material y texto- se extendió también al mundo del libro: se empezó a utilizar como sinónimo de index, el equivalente de los términos griegos sittybon o sillybos, para referirse a la etiqueta de un rollo de papiro ${ }^{32}$; esta, que contenía los datos necesarios para identificar el contenido del volumen sin necesidad de abrirlo, se colgaba del umbilicus o se pegaba en la parte superior del papiro de manera que sobresaliera ${ }^{33}$. A partir de ahí denominó también el texto que figuraba en las etiquetas, que, por lo poco que se sabe, aportaba datos sobre el autor, el contenido o el título de la obra, a veces el número que ocupaba el rollo en el conjunto; es decir, no era estrictamente el título en nuestro sentido moderno sino todo aquello que valiera para identificar el rollo.

Ovidio utiliza titulus con frecuencia en el conjunto de su obra (62 veces); muy a menudo con el significado de 'distinción', título de gloria que un hombre posee y que por lo tanto lo define. También alguna vez lo emplea con el sentido de 'inscripción' (Ep. V 26 y XIV 128, p. ej.), acepción que aparentemente corresponde a Trist. III 3.77. Además lo incluye en pasajes cuyo tema es el libro: estos son los primeros testimonios en los que designa la etiqueta e incluso el 'título' en su sentido moderno (Martelli 2013, p. 158). Conviene un análisis más detallado de estos casos.

Como empezaron a hacer otros poetas a partir de Catulo (1 y 22), Ovidio presta enorme atención al libro como objeto material que sirve de soporte a

${ }^{32}$ El $O L D$ distribuye sus acepciones en siete apartados; entre ellos aparece la acepción de 'título' y 'encabezamiento', pero no la propiamente de 'etiqueta', que, según Moussy, sería previa.

${ }^{33}$ Los escasísimos restos conservados de libros en latín de esta época hace que todas las suposiciones sobre los rasgos materiales de los libros descansen en la hipótesis de que eran similares a los griegos, si bien hay conciencia de que al menos en la época augústea tenían sus propias particularidades. Cf. Dorandi 1984, Moussy 1997 y Caroli 2007. 
su obra poética y en el que encuentra una imagen de su propia poesía ${ }^{34}$. En Tristia los rasgos materiales del libro se corresponden con su contenido y la apariencia de su autor: en I 1 el poeta se dirige a él, puesto que lo ha enviado a Roma, y le anima a recorrer sus lugares favoritos para así poder tocarlos con los pies de sus versos ya que no puede hacerlo con sus auténticos pies (Trist. I 1.15-16; Newlands 1997, p. 58; Hardie 2002, pp. 297-300). Explícitamente el libro es el representante de su autor (Trist. I 1.55-57) y, como tal, su aspecto externo es acorde con la apariencia del poeta, un desdichado exiliado alejado de la civilización, marcado por la tristeza y el luto (I 1.3-14), y con el tipo de poesía que contiene, la elegía de lamento (Claasen 1990, pp. 111-112). En el poema que encabeza este mismo libro III, Ovidio da un paso más al conceder voz al libro: este cuenta en primera persona cómo, llegado a Roma, es rechazado por todas las bibliotecas a las que intenta entrar y es excluido de los círculos culturales de la Roma augústea (Claasen 1990, Newlands 1997, pp. 58-59), como de hecho le ocurría a él mismo. De nuevo la apariencia material del rollo corresponde a la condición de su autor y su obra, como ilustran Trist. III 1.11-16 y 55.

Está claro que en estos pasajes titulus pertenece al vocabulario del rollo de papiro, pero no se sabe si designa la etiqueta o el texto que se escribía en ella para identificar el libro, que no coincidía exactamente con el término moderno 'título'.

Realmente solo en dos ocasiones parece que titulus se refiere al texto: Ars III 343 (Deue tribus libris, titulus quos signat Amorum,...) y Pont. I 1.16-17 (hablando del nuevo libro y comparándolo con Tristia: non minus hoc illo triste, quod ante dedit. / rebus idem, titulo differt).

En los demás casos es más probable que se refiera a la etiqueta, que al fin y al cabo parece una acepción previa (recordemos que los textos de Ovidio son los primeros en asociar el término al mundo librario, siendo index el vocablo habitual, Moussy 1997, p. 6). En este sentido interpretamos Trist. I 1.7: nec titulus minio, nec cedro carta notetur; el poeta señala que el descuido y la miserable apariencia de su autor exiliado llega a afectar incluso a la etiqueta, que no será teñida con cinabrio, como ocurría con las de otros li-

${ }^{34}$ Williams 1992 analiza Trist. I 1, después de mencionar de Catulo 1.1-2 y 22, Cinna, fr. 11, Lígdamo ([Tib.] III 1.7-14), Hor., Ep. I 20, texto respecto al que Ovidio realiza aquí una deliberada inversión en términos negativos, y Marcial, III 2 y VII 11. Cf. también Newlands 1997. 
bros $^{35}$. Pont. IV 13.7 es también claro: ... ut titulum chartae de fronte reuellas, ... En Trist. I 1.61 (nec te, quod uenias magnam peregrinus in urbem / ignotum populo posse uenire puta. / ut titulo careas, ipso noscere colore) no hay ninguna razón para interpretar titulus como otra cosa que la etiqueta que sirve para identificar el rollo; de hecho, la referencia al color parece indicar que se habla de rasgos externos del libro (prescindiendo de que color pueda adquirir un sentido figurado). En cuanto a los otros pasajes no hay ningún indicio que permita concluir que titulus se refiera al texto presentativo de la etiqueta y no a esta en general ${ }^{36}$. No se demuestra tampoco que titulus se use para designar el título propiamente dicho sino que puede ser todo aquello que sirve para identificar el rollo. Persiste, por tanto, la vaguedad característica del término, válido para el soporte material, sea cual sea, y el texto. A este propósito es iluminador el texto de Trist. III 1.9, donde dice el propio libro: Inspice quid portem: nihil hic nisi triste uidebis; el contenido triste es tan definitorio que pasará a ser el título de la obra.

Volviendo a III 3, comprobamos que titulus y libelli aparecen en el mismo verso, el 77. Tras la afirmación hoc satis in titulo est la partícula etenim introduce una identificación explícita entre los libelli, en la posición final del verso, y un objeto físico, monumenta; ambos temas, libros y monumentos, constituyen un espacio apropiado para la presencia de la palabra titulus.

A la vista de lo expuesto, nuestra propuesta es que en el verso III 3.77 (hoc satis in titulo est) Ovidio juega con las múltiples interpretaciones del término titulus, que, como hemos visto, se basan fundamentalmente en su carácter presentativo: una distinción concedida a un hombre, una inscripción

${ }^{35}$ Cf. Caroli 1997, pp. 46-48, que repasa varios testimonios gráficos sobre las etiquetas coloreadas, como el fresco de Terencio Neo y su esposa.

${ }^{36}$ Cuando el poeta anima al libro a contestar a los que lo rechazan que solo tienen que mirar el titulus para comprobar que no se trata del Ars amatoria (Trist. I 1.67 «inspice» dic «titulum. non sum praeceptor amoris») tampoco hay nada que permita afirmar taxativamente que se refiera al título propiamente dicho y no simplemente a un texto que presenta al autor o a la etiqueta identificativa, que ya con su apariencia, sin color, como acaba de decir, marca su carácter triste. En Trist. I 1.109-110 (cetera turba palam titulos ostendet apertos, / et sua detecta nomina fronte geret) es nomina la palabra que se utiliza para designar el título propiamente dicho. En Pont. III 6.50 (fortunamque meam metuens, non uindicis iram / terrebar titulo nominis ipse mei) la presencia de ambos sustantivos se reparte de manera similar, como ocurre en Rem. 1: Legerat huius Amor titulum nomenque libelli: es incierto si titulum y nomen son sinónimos o si el primero se refiere a la etiqueta en la que está incluido el segundo. Cf. Williams 1992, pp. 184-185. Otros ejemplos similares: Trist. I 1.109-110 o Pont. IV 13.7-8. 
que identifica un monumento conmemorativo..., pero también una etiqueta y el texto que va en ella, el título propiamente dicho o cualquier otra información que valga para identificar la obra y, en virtud de la equivalencia entre poeta y libro, a su autor. El libro de Tristia es descrito tantas veces como triste y fúnebre ${ }^{37}$ que un epitafio podría ser una ajustada carta de presentación para él, sobre todo porque contiene datos identificativos precisos, el nombre del poeta y el género de poesía que cultiva ${ }^{38}$. Igual que un epitafio es un $t i$ tulus ligado a un monumento y a la persona a la que se ha dedicado, el texto de la etiqueta -también sujeto al rollo- cumple la misma función respecto a los libelli, que, aunque han perjudicado a su autor, constituyen auténticos monumentos que le definen y le aseguran la inmortalidad ${ }^{39}$.

Este tipo de juegos no es raro en Ovidio. En el primer verso de Trist. I 1 hay un ejemplo con liber -'libre' y 'libro'-, curiosamente un término que también puede aludir al objeto mismo que el lector tiene en su mano (Newlands 1997, p. 72; Hardie 2002, p. 298 $)^{40}$.

37 Ya hemos citado Trist. III 1.9; además en el propio III 3 leemos et fient ipso tristia fata loco (v. 38) y la palabra final, Vale, que al fin y al cabo resulta ser la despedida que aparece en muchos epitafios. Cf. Gómez Pallarés 1998.

${ }^{38}$ El término libelli, utilizado por Ovidio para sus libros elegiacos, puede perfectamente aludir a Tristia. La concesiva quamuis nocuere no necesariamente implica que solo se refieran a los libros del Ars amatoria, como sostiene Herescu 1958, p. 430. Como argumento puede valer la expresión muy similar de IV 1.35: nos quoque delectant, quamuis nocuere, libelli; el verso sintetiza el pasaje completo (Trist. IV 1.27-35) en el que se justifica por seguir cultivando la poesía a pesar de que esta es la causa de su desgracia.

39 A diferencia de otros autores no consideramos que Ovidio exprese repentino desdén contra los versos 73-76. Según Huskey (2005, p. 382), p. ej., Ovidio ha visto que el epitafio de Tibulo en I 3 no era capaz de reflejar quién era realmente Tibulo (ya hemos señalado antes que no alude a la poesía) y él en el suyo pretende paliar esta deficiencia insistiendo en su actividad como poeta, pero se da cuenta de que, a pesar de este intento, un epitafio no puede por su brevedad dar cuenta exacta de sus méritos, cualidades u obras, y por eso señala que serán sus libros los auténticos monumentos. Sin embargo, en el texto no hay marcas adversativas, etenim no presenta ese valor sino el de una aclaración. Es cierto que la presencia de los comparativos (especialmente magis, porque maiora puede ser leído como un intensivo) implica un segundo término, pero este no tiene por qué ser el titulus, definido en todas sus acepciones como un simple presentador, sino los monumentos 'literales' (a semejanza de la expresión horaciana exegi monumentum aere perennius), quizá los promovidos por Augusto, como dicen Houghton 2013, p. 361 e Ingleheart 2015, p. 296.

${ }^{40}$ Cf. Ingleheart 2015, p. 283, n. 22 sobre los juegos de palabras con Tristia, el título propiamente dicho: II 133 y 493; IV 10.112; V 1.47, etc. 
En cualquier caso, el titulus, sea una inscripción o el texto que figura en una etiqueta de un rollo, debe ser breve, tal y como el propio poeta afirma. Pero, en términos de epitafio, resulta chocante que Ovidio encargara a su esposa grabar con caracteres grandes estos cuatro versos, siendo su urna, como especifica en el v. 65 , pequeña ${ }^{41}$; sería difícil cumplir con estas instrucciones. Esta incongruencia reduce el monumento funerario junto con su inscripción a un objeto no real, ilusorio. Y lo cierto es que estos cuatro versos también parecen ser excesivos para una etiqueta, que, por lo que sabemos, eran de dimensiones reducidas (p. ej., $3,3 \times 13,4 \mathrm{~cm}$.) y contenían un texto escueto (Dorandi 1984 y Caroli 2007). Sin embargo, ya en otros lugares hemos visto que Ovidio utiliza figuradamente la apariencia externa del rollo de papiro; incluso, como hemos visto antes, apunta la posibilidad de que no lleve etiqueta (Trist. I 1.61), aunque luego lo desmienta al comentar su apariencia. En todo caso, el libro sí es un objeto real, que existe y está en las manos del lector, $y$, en consecuencia, a diferencia de su imaginado monumento funerario en las afueras de Roma, puede perfectamente cumplir su misión conmemorativa e inmortalizadora (Newlands 1997, pp. 59-60).

Un somero análisis de la deixis temporal del poema confirma esta diferencia: Ovidio utiliza verbos en futuro alternando con imperativos con proyección de futuro para describir su agonía, la tristeza de su esposa, o los honores que esta le rendirá, pero en los vv. 77-79, que se refieren a su libro, usa presentes (est, sunt, confido), que apuntan a que se trata de realidades existentes en el tiempo de la codificación ${ }^{42}$.

Todo ello casa perfectamente con la preocupación que el poeta exhibe en Tristia por la recepción de sus nuevas obras, como recuerda Newlands (1997, p. 74), que señala que el libro III está impregnado de esta inquietud; empieza

${ }^{41}$ Sobre la interpretación de este deseo, que el epitafio se inscriba en grandes caracteres, cf. Ingleheart (2015, pp. 299-300), que lee el contraste de su parua urna y de sus libelli con la monumentalidad material proyectada por el emperador como una respuesta al Mausoleo de Augusto. Por otra parte, obsérvese que el diminutivo, utilizado por él mismo para sus obras elegiacas, corresponde al pequeño tamaño de su urna funeraria (parua), pero contrasta con la magnitud y prolongación de su efecto (maiora, diuturna magis).

${ }^{42}$ A la vez la deixis de las personas en estos versos reproduce de alguna manera el juego entre presencia y ausencia ya señalado en el epitafio: confido en primera persona y los pronombres personales ego y mihi dejan paso a una referencia a sí mismo en tercera persona: daturos / nomen et auctori tempora longa suo, que se explica por la utilización de un infinitivo de futuro (daturos): en ese momento el poeta estará muerto y, por tanto, ausente. 
y acaba con poemas en los que el libro es el objeto esencial: III 1 (el libro, dotado de voz y trasunto de su autor, llega a Roma y es rechazado por las bibliotecas) y 14 (la carta a un amigo suyo que ha guardado sus libros).

En suma, si aceptamos la multiplicidad del término titulus, el deíctico hic podría referirse al libro mismo que el lector tendría en sus manos. Nos encontramos ante un caso complejo: en principio, podría definirse como exofórico, el rollo de papiro equivalente al monumento funerario; pero, en virtud de las equivalencias descritas, el libro material representa la obra poética de Ovidio (en este caso, restringida al género elegíaco, algo sobre lo que volveremos luego), por tanto, no es algo ajeno al discurso: su utilización se podría describir como 'recognitional', según la terminología ya utilizada de Diessel. Se está activando un conocimiento compartido entre el emisor y el receptor del poema: ambos saben que estos cuatro versos se han incluido dentro de una carta que es un poema, a su vez inserto en un libro con unas características poéticas y materiales determinadas. A este lugar, a la poesía ovidiana y al libro que la contiene -el carácter conmemorativo depende de su existencia como libro- también se refiere el hic, el lugar donde 'yace' el poeta.

No resulta descabellado admitir semejante grado de sofisticación en Ovidio. Como muestra puede valer el epitafio de Met. XIV 443-444, que Eneas dedica a su nodriza Cayeta y que también comienza con hic:

Finierat Macareus, urnaque Aeneia nutrix condita marmorea tumulo breue carmen habebat HIC ME CAIETAM NOTAE PIETATIS ALVMNVS EREPTAM ARGOLICO QUO DEBVIT IGNE CREMAVIT.

Este caso presenta una complicación añadida puesto que incorpora la presencia del texto de Virgilio, pero ofrece un excelente ejemplo de la multiplicidad de valores del deíctico (Hinds 1998, pp. 107-108). Lo más sobresaliente es que aquí hic no solo resalta la importancia del lugar geográfico que debe su nombre a la tumba de la nodriza -no olvidemos que en Virgilio es una etiología que explica el nombre geográfico- sino que se aplica también al lugar que la aparición de Cayeta ocupa dentro de las Metamorfosis; y es relevante porque Ovidio ha introducido un cambio sustancial respecto a la Eneida: Virgilio menciona Cayeta - el lugar-al final del libro VI, en el v. 900, como el siguiente destino de Eneas tras salir del inframundo. El libro VII comienza con la etiología del nombre (VII 1-4); así pues, la presencia de Cayeta está repartida entre el final del libro VI y el comienzo del VII, el 
centro de la Eneida. En las Metamorfosis también hay dos alusiones a Cayeta pero están separadas por casi trescientos versos que ocupan las narraciones de Macareo: como en la Eneida, Eneas sale del inframundo y en ese momento Ovidio se refiere a Cayeta mediante una perífrasis (Met. XIV 154-157):

Talia conuexum per iter memorante Sibylla sedibus Euboicam Stygiis emergit in urbem Troius Aeneas sacrisque ex more litatis litora adit nondum nutricis habentia nomen.

Pero su segunda aparición no se producirá hasta los versos en los que incluye su epitafio. De esta manera Ovidio, reconociendo el lugar central de la Eneida, deliberadamente desarticula esa disposición. Por tanto, hic adquiere el mismo valor doble que, según Hinds, había adquirido otro deíctico, nondum, en el v. 157. Ovidio hace notar que cuando Virgilio dice que Eneas se dirige a Cayeta, este lugar aún no se llamaba así, puesto que aún no había enterrado allí a la nodriza, según la etiología que sigue al comienzo del libro VII. Pero a la vez indica que en su propia obra aún no va a aparecer la referencia a la muerte de Cayeta sino que habrá que esperar otros trescientos versos. El nondum apunta a momentos distintos en niveles distintos: en el tiempo mítico, señalando la infracción en el relato de Virgilio; y en la secuencia temporal de su propia obra, donde rompe el decurso de la historia insertando los relatos de Macareo.

\section{Conclusión}

El análisis constata la multirreferencialidad de hic (visible también en otros deícticos de persona y tiempo) en el epitafio según la situación pragmática del acto enunciativo correspondiente: exofórico (cualquier lugar en el que se sitúe el monumento), anafórico (Roma si atendemos a la carta a su esposa), 'recognitional' (si consideramos su pertenencia a un poema).

Pero la inscripción ofrece todavía algunos puntos llamativos. Se ha señalado de manera prácticamente unánime que Ovidio limita en ella su quehacer poético a la elegía, en concreto a la amorosa, y omite las grandes obras. En efecto, los versos resaltan esa faceta del poeta ${ }^{43}$. En primer lugar, el sintagma

${ }^{43}$ Cf. fundamentalmente Herescu 1958, p. 427; Videau-Delibes 1991, pp. 342-343; Huskey 2005, p. 379; Houghton 2013, p. 356, e Ingleheart 2015, pp. 294-295, que recogen estos elementos metapoéticos y ofrecen distintas interpretaciones. 
tenerorum lusor amorum (que reaparece en Trist. IV 10.1) resume como lo esencial de su carrera la poesía amorosa de corte calimaqueo. En segundo lugar, el nombre del poeta, Naso, es el que utiliza en sus obras de elegía amorosa. Por otra parte, Ovidio se dirige a todo el que pase por allí en virtud de que alguna vez ha amado (quisquis amasti), lo que, como ya dijimos, define a este como lector de su Ars amatoria. Asimismo, en el deseo que el transeúnte debe expresar-NASONIS MOLLITER OSSA CVBENT, una variante de la habitual fórmula sit tibi terra leuis-molliter se ha interpretado como una indicación del género elegiaco al que frecuentemente se atribuye el adjetivo mollis. Se ha apuntado además la probable relación con las palabras que Virgilio pone en boca de Cornelio Galo en Ecl. X 33: o mihi tum quam molliter ossa quiescant? (Ingleheart 2015, p. 295). Por último, la alusión a su desgracia (quamuis nocuere, v. 79) pone de nuevo bajo el foco al Ars amatoria.

Si en su epitafio Ovidio, a diferencia de Tibulo, quiere reflejar una imagen literaria determinada (quizá influido por su conocimiento de otros epitafios literarios como los que supuestamente transmitió Varrón en el De poetis), está claro que buscaba la asociación de su nombre al género concreto de la elegía amorosa. No resulta extraño si pensamos el cuidado con el que construyó su carrera y revisó su obra; podemos conjeturar que buscó cerrar un círculo: el comienzo y el final de su carrera están ligados a la elegía, una amorosa, otra de lamento, ambas estrechamente relacionadas (Hardie 2002, p. 63; Fedeli 2003, pp. 20-22, Houghton 2013, pp. 350-351).

En este sentido el carácter metapoético del epitafio -y la sofisticación del poema- se ve reforzado por la interpretación de un uso 'recognitional' que identifica el referente de hic como el propio rollo de papiro que el lector tiene en sus manos, a la vez imagen de su poesía y representante del autor. Pero además esta interpretación fortalece el efecto irónico al ligar el epitafio al libro material: Ovidio, el poeta de la elegía amorosa, cuya desgracia ha surgido precisamente de su talento en este terreno, 'yace' en este libro, un libro elegiaco, pero triste, tan triste que la etiqueta que sirve para identificarlo podría contener un epitafio; sin embargo, a pesar de su carácter fúnebre, visible incluso en su apariencia externa, este libro será capaz de conseguir que Ovidio, el poeta del amor, quede inmortalizado como tal (a pesar de Augusto).

\section{BIBLIOGRAFÍA}

Barchiesi, A. 1997: «Ecphrasis», en Martindale, C. (ed.), The Cambridge Companion to Virgil, Cambridge, pp. 271-281. 
Caroli, M. 2007: Il titolo iniziale nel rotolo librario greco-egizio, Bari.

Claasen, J. M. 1990: «Ovid's wavering identity: personification and depersonalisation in the exilie poems», Latomus 49, pp. 102-116.

Claasen, J. M. 1996: «Exile, death and immortality: voices from the grave», Latomus 55, pp. 577-590.

Claasen, J. M. 2008: Ovid revisited: the poet in exile, Londres.

Dahlmann, H. 1963: Studien zu Varro «De poetis», Wiesbaden.

Diessel, H. 1999: Demonstratives: Form, Function, and Grammaticalization, Ámsterdam.

Dinter, M. 2011: «Inscriptional intermediality in Latin Elegy», en Keith, A. (ed.), Hellenistic Epigram and Latin Elegy, Cambridge, pp. 7-18.

Dorandi, T. 1984: «Sillyboi», Scrittura e Civiltà 8, pp. 185-199.

Ernout, A. y Thomas, F. 1972²: Syntaxe latine, París.

Fedeli, P. 2003: «L'elegia triste di Ovidio come poesia di conquista», en Gazich, R. (ed.), Fecunda licentia. Tradizione e innovazione in Ovidio elegiaco, Atti delle Giornate di studio (Univ. Cattolica del Sacro Cuore, Brescia-Milano, 16-17 aprile 2002), Milán, pp. 3-35.

Gómez Pallarés, J. 1998: "Ovidius Epigraphicus: Tristia lib.1, con excursus a 3, 3 y 4, 10», en Schubert, W. (ed.), Ovid. Werk und Wirkung. Festgabe für Michael von Albrecht zum 65. Geburtstag, Frankfurt, pp. 755-773.

Hardie, P. 2002: Ovid's Poetics of Illusion, Cambridge.

Herescu, N. I. 1958: «Le sens de l'épitaphe ovidienne», en Herescu, N. I. (ed.), Ovidiana, Recherches sur Ovide, París, pp. 420-442.

Hinds, S. 1998: Allusion and Intertext: Dynamics of Appropriation in Roman Poetry, Cambridge.

Houghton, L. 2009: «Tot Monumenta? T. R. Ramsby, Textual Permanence. Roman Elegists and the Epigraphic Tradition», CR 59, pp. 142-143.

Houghton, L. B. T. 2013: «Epitome and eternity: some epitaphs and votive inscriptions in the Latin love elegists», en Liddel, P. y Low, P. (eds.), Inscriptions and their Uses in Ancient Literature, Oxford, pp. 349-364.

Huskey, S. 2005: «In Memory of Tibullus: Ovid's Remembrance of Tibullus 1.3 in Amores 3.9 and Tristia 3.3», Arethusa 38, pp. 367-386.

Ingleheart, J. 2015: «Exegi Monumentum: Exile, Death, Immortality and Monumentality in Ovid, Tristia 3.3.», CQ 65, pp. 286-300.

Lascu, N. 1971: «Hic ego qui iaceo (Epigrafie și poezie)», Pontica 4, pp. 211-219.

Lassère, J.-M. 2005: Manuel d'épigraphie romaine, París.

Lattimore, R. 1942: Themes in Greek and Latin Epitaphs, Urbana.

Levinson, S. C. 1989 (= 1983): Pragmática, Barcelona.

Maltby, R. 1991: A Lexicon of Ancient Latin Etymologies, Leeds. 
Martelli, F. K. A. 2013: Ovid's Revisions: The Editor as Author, Cambridge - Nueva York.

Moussy, C. 1997: «Les appellations latines de titres de livres», en Fredouille, J.-C., Goulet-Cazé, M. O., Hoffmann, P. y Petitmengin, P. (eds.), Titres et Articulations du texte dans les ouvres antiques. Actes du colloque de Chantilly, 13-15 décembre 1994, París, pp. 1-7.

Nelis-Clément, J. y Nelis, D. 2013: «Furor epigraphicus: Augustus, the Poets and the Inscriptions», en Liddel, P. y Low, P. (eds), Inscriptions and Their Uses in Greek and Latin Literature, Oxford, pp. 317-347.

Newlands, C. 1997: «The Role of the Book in Tristia 3.1», Ramus 26, pp. 57-79.

Oliensis, E. 1997: «Return to Sender: The Rhetoric of nomina in Ovid's Tristia», Ramus 26, pp. 172-193.

Oomen, U. 1987(=1975): «Sobre algunos elementos de la comunicación poética», en Mayoral, J. A. (ed.), Pragmática de la comunicación literaria, Madrid, pp. 137-149.

Owen, S. G. (ed.) 1915: Ovid. Tristia, Ibis, Epistulae Ex Ponto, Halieutica, Fragmenta, Oxford.

Ramsby, T. 2005: «Striving for Permanence: Ovid's Funerary Inscriptions», CJ 100, pp. 365-391.

Ramsby, T. 2007: Textual Permanence: Roman Elegists and the Epigraphic Tradition, Londres.

Schmidt, V. 1985: «Hic Ego Qui Iaceo: Die Lateinischen Elegiker Und Ihre Grabschrift», Mnemosyne 38, pp. 307-333.

Schmidt, S. J. 1987 (= 1978): «La comunicación literaria», en Mayoral, J. A. (ed.), Pragmática de la comunicación literaria, Madrid, pp. 195-212.

Siewierska, A. 2004: Person, Cambridge.

Svenbro, J. 1988: Phrasikleia: anthropologie de la lecture en Grèce ancienne, París.

Trapp, J. B. 1973: «Ovid's Tomb», Journal of the Warburg and Courtauld Institutes 36, pp. 35-74.

Videau-Delibes, A. 1991: Les Tristes d'Ovide et L'élégie romaine. Une poétique de la rupture, París.

Williams, G. D. 1992: «Representations of the Book-Roll in Latin Poetry: Ovid, Tr.1, 1, 3-14 and related Texts», Mnemosyne 45, pp. 178-189.

Fecha de recepción de la primera versión del artículo: 10/07/2018

Fecha de aceptación: 11/09/2018

Fecha de recepción de la versión definitiva: 20/09/2018 